\title{
Escola Nacional de Energia Popular: educação popular e suas contribuições na formação de educadores do campo
}

National School of Popular Energy: popular education and their contributions to the degree in rural education

Odalia Martins Machado

Fernanda Maria Coutinho de Andrade

Maria Jose de Souza

Fabrício Vassalli Zanelli

Resumo: A Educação Popular e os movimentos sociais em suas trajetórias acumulam experiências educativas de formação integral. O objetivo deste trabalho é descrever as práticas educativas populares, promovidas por movimentos sociais, em espaço não formal de aprendizagem e refletir sobre o potencial formador destas práticas. A experiência da Escola Nacional de Enegia Popular, organizada e gerida por movimentos sociais, localizada em Viçosa, MG. Por meio da observação participante, de entrevistas e pesquisa documental e bibliográfica foi possível descrever práticas educativas populares e refletir sobre as contribuições à Educação do Campo.

Palavras Chave: Educação não formal; Práticas educativas, Educação do Campo

Abstract: The training of rural educators emerges as a demand for quality education for rural peoples. Popular education and social movements in their trajectories accumulate educational experiences of integral formation. The objective of this work was to describe the popular educational practices, promoted by social movements, in a non-formal learning space and reflecton the potencial of forming these practices. The experience of the National School of Popular Education, organized and managed by social movements, located in Viçosa, MG, was studied. Through participant observation, interviews and documentary and bibliographic research, it was possible to describe popular educational practices and reflect on contributions to Rural Education.

Keywords: Non-formal education; Educational practices, Rural Education;

\section{Introdução}

De acordo com a Lei de Diretrizes e Bases da Educação Nacional (LDB), a educação não se restringe aos processos de ensino e aprendizado nas escolas. A LDB reconhece que a educação abrange outros espaços formativos, como por exemplo, aqueles conduzidos pelos movimentos sociais (BRASIL, 1997). Cabe ressaltar, que os movimentos sociais trazem a concepção ampla de educação que envolve processos formais e não formais e visam a formação humana integral (BATISTA, 2016).

O Departamento de Educação da Universidade Federal de Viçosa (UFV) oferece a partir de 2014 o curso de graduação em Licenciatura em Educação do 
Campo (LICENA). A proposta é a formação de educadores (as) com atuação profissional que, além da docência, possibilite a gestão dos processos educativos que acontecem nas escolas do campo e em outros espaços socioeducativos (PPC-Licena, 2018).

A proposta é a formação de educadores (as) com atuação profissional que, além da docência, possibilite a gestão dos processos educativos que acontecem nas escolas do campo e em outros espaços socioeducativos .

$\mathrm{Na}$ atualidade brasileira a Educação do Campo pode ser identificada como uma das propostas educativas da concepção de Educação Popular (PALUDO, 2012). Por isso, um dos pilares da LICENA, de acordo com seu Projeto Pedagógico, é a Educação Popular (PPC-Licena).

Muitos desafios são colocados a Educação do Campo, dentre estes destacamos a compreensão das práticas educativas construídas coletivamente pelos movimentos sociais, nos processos de Educação Popular, sobretudo nos espaços não formais de ensino e aprendizagem. Segundo Silva (2015), a produção pedagógica dos movimentos sociais ao longo da história constitui-se como teoria pedagógica cujos fundamentos estão presentes no movimento pedagógico da Educação do Campo.

Muitas experiências em Educação Popular acontecem pelo Brasil. Neste texto destacamos a experiência da Escola Nacional de Energia Popular (ENEP), fundada e gerida por diversas organizações sociais da Zona da Mata de Minas Gerais. A Escola visa ser espaço educativo de formação humana integral e de divulgação de Tecnologias Sociais Populares. Na concepção da ENEP está o trabalho como princípio educativo, promovido em coletivo. Assim, este espaço vem sendo construído por meio da prática de multirões que é caminho para a realização das ações e momento de reflexão, aprendizado e formação política.

A proposta desse trabalho foi descrever as práticas educativas populares adotadas na ENEP, que é espaço educativo não formal, bem como refletir sobre o potencial formador destas práticas. 


\section{Movimentos sociais e suas atuações}

A trajetória histórica dos movimentos sociais é marcada por processos intensos de luta e reconhecimento dos direitos das camadas populares. Os movimentos sindicais, movimentos de agricultores (as), movimentos sem terra, movimentos quilombolas, movimentos indigenas, movimentos de trabalhores (as), dentre tantos outros, que reivindicam e lutam por uma educação que atenda as esferas populares, acesso a terra, saúde, etc. Lutas comuns e específicas. Direitos negados durante muitos anos.

Os movimentos nos convidam a refletir sobre suas práticas educativas, na compreensão de um novo paradigma de educação. Educação autêntica, que ensina, valoriza e transforma. Nesse campo de discussão é imprescindível a compreensão dos movimentos sociais do campo como fenômeno de experiências educativas, assim como na busca pelo resgate da relação trabalho/educação, que se reconfigura na reflexão/ação acerca da importância e do sentido pedagógico dos movimentos sociais (BATISTA, 2016).
A educação, enquanto forma de ensino-aprendizagem, é adquirida ao longo da vida dos cidadãos e, sob o ponto de vista de alguns autores, pode ser dividida em três diferentes formas: a educação formal desenvolvida nas escolas; a educação informal, transmitida pelos pais e outros tipos de convívios com a sociedade em geral; e a educação não formal, que proporciona a aprendizagem de conteúdos da escolarização formal em espaços para além da sala de aula, nos quais as atividades desenvolvidas devem ser direcionadas e ter um objetivo definido (GONH, 1999, p. 95).

Nessa perspectiva, os processos educativos dos movimentos sociais, acontecem, na maioria das vezes, fora das instituições escolares, se caracterizam como educação não formal e ocupam espaço na reflexão educacional e sociológica do Brasil e de outros países da América Latina. Existem muitos conceitos para a educação não formal, mas de modo geral refere-se ao processo educativo que acontece fora do espaço formal de educação, de forma complementar, é flexível, não segue necessariamente todas as normas e diretrizes estabelecidas pelo governo federal, inclui diferentes dimensões do conhecimento, além daquelas abordadas pela educação formal (SILVA, 2015). 
Os movimentos sociais do campo promovem suas ações como tarefa humanizadora, onde os sujeitos são protagonistas de suas histórias, trazendo em sua concepção uma educação, diferenciada, libertadora e transformadora (SILVA, 2015).

Portanto, ao passo que se fortalecem na construção de um ambiente político, social e cultural na luta por direitos, os movimentos sociais protagonizam dinâmicas formativas e organizativas reconhecidas por seu caráter educativo.

\section{Educação Popular}

De acordo com Paludo (2012):

a Educação Popular nasce e se firma como teoria e práticas educativas alternativas às pedagogias, constituída pelo emponderamento, organização e protagonismo dos trabalhadores do campo e da cidade. (PALUDO, 2012, p. 32).

Segundo Silva (2016), em suas concepções, a Educação Popular inspirada na Pedagogia do Oprimido de Paulo Freire, é uma educação libertadora, nascida e fortalecida no seio das classes populares e de seus movimentos sociais que buscam romper ou superar a concepção de educação "bancária", largamente utilizada na educação escolar, criticada por ser funcional aos setores dominantes, numa perspectiva de consolidar o processo hegemônico de dominação econômica, ideológica e cultural.

Silva (2016) complmenta ainda que:

a Educação Popular busca proporcionar aos indivíduos compreensão crítica, que possibilite a práxis transformadora da realidade, social, política e cultural. Sua proposta pedagógica tem por base a problematização, o diálogo e a participação, o que é coerente com a "Pedagogia Libertadora" proposta por Freire (FREIRE, 1987). (SILVA, 2016, p. 35).

Segundo Paludo (2012), no Brasil, é possível identificar três momentos fortes de constituição da Educação Popular. Esses momentos acompanham o processo de desenvolvimento brasileiro. Ao longo desta trajetória foi-se construindo uma concepção de educação que se questiona sobre as finalidades 
do processo educativo e dos conteúdos presentes nos processos educativos para os povos do campo (SILVA, 2015).

Desse forma a Educação Popular se materializa na formação libertadora e transfromadora, onde seu principal intuito é a transformação da realidade. Essa reflexão indica que a Educação Popular é comprometida e participativa, em busca de igualdade e adequada às especificidades das camadas populares, muitas vezes resistindo ao paradigma do modelo hegemônico.

\section{Educação do Campo e práticas educativas}

A Educação do Campo envove importantes experiências existentes no Brasil, protagonizada pelos próprios sujeitos populares. Seus impulsionadores são os movimentos populares do campo (PALUDO, 2012). Silva (2015) protagoniza a produção pedagógica dos movimentos sociais ao longo da história como teoria pedagógica cujos fundamentos estão presentes em várias iniciativas atuais e presentes no movimento pedagógico da Educação do Campo.

Assim, embora o termo e o conceito "Educação do Campo" tenham sido construídos a partir da década de 1990, os referenciais que fundamentam as diferentes práticas educativas têm suas raízes e aprendizagens na Educação Popular (SILVA, 2015). A produção pedagógica dos movimentos sociais ao longo da história foi gestando o repertório de conhecimentos e práticas que foram resgatadas e sistematizadas pelos movimentos sociais atuais, constituindo assim a teoria pedagógica cujos fundamentos estão presentes em várias iniciativas que temos hoje no movimento pedagógico da Educação do Campo (PALUDO, 2015).

Segundo Caldart (2012) a Educação do Campo surge das experiências e processos educativos presentes "no chão dos assentamentos" junto com a luta pelo acesso à terra no contexto da reforma agrária. E são essas práticas e processos educativos, presentes nesses espaços que orientam a didática da Educação do Campo, que deve estar voltada para as realidades das/os estudantes, onde o currículo, a didática e as metodologias das/os educadoras/es do campo, reconheçam as suas especificidades e as diversidades presentes nestes espaços educativos, que são também espaços de produção da vida. 
A Educação do Campo prima pela educação com qualidade social, que considere e respeite as diversidades, promova e valorize sem a pretensão de homogeneizá-la; que estimule a autoestima e que a sistematização dos conhecimentos seja construída a partir dos saberes acumulados pelo coletivo da comunidade campesina (ARROYO, CALDART \& MOLINA, 2004). O exercício da

docência em escolas do campo implica em práticas pedagógicas concebidas na compreensão da diversidade que caracteriza esse espaço territorial específico (BRASIL, 1997; BRASIL, 2002).

As Ledoc's (Licenciaturas em Educação do Campo) surgem como proposta de formação de professores em docência multidisciplinar para atuação nas escolas e na educação do campo.

A Universidade Federal de Viçosa, oferece o curso de Licenciatura em Educação do Campo, com habilitação em Ciencias da Natureza (LICENA) que tem como eixos norteadores a Agroecologia, a Educação Popular, o Trabalho como Princípio Educativo e as Alternâncias Educativas (PPC-Licena, 2018). A LICENA prima pela educação contextualizada, práticas pedagógicas que atendam as demandas e diversidades do campo, o diálogo de saberes e a formação humana integral, contribuindo com a visão crítica, reflexiva da realidade contribuindo com ações transformadoras.

\section{Metodologia}

Esta pesquisa foi desenvolvida na Escola Nacional de Energia Popular (ENEP), situada na comunidade da Colônia, zona rural do município de Viçosa/MG. Nesta pesquisa de campo, optou-se pela observação das reuniões mensais da Coordenação da ENEP, a fim de compreender a dinâmica de organização do grupo, os processos de tomada de decisão coletiva e a elaboração da agenda de atividades mensais da Escola. As observações foram anotadas no Caderno de Campo.

A Observação enquanto técnica exige treino disciplinado, preparação cuidada e conjuga alguns atributos indispensáveis ao observador, investigador, tais como atenção, sensibilidade e paciência. Tem por referência o(s) objetivo(s), favorecendo uma abordagem indutiva, com natural redução de "pré-conceções". A 
possibilidade de vir a clarificar aspetos observados e anotados em posterior entrevista e em observações mais focalizadas, constitui um ganho excepcional face a outras técnicas de investigação. (CORREIRA, 2009, p. 35).

Também foi realizada a entrevista semiestruturada com alguns membros organizadores/fundadores da ENEP visando coletar informações sobre a história da escola. A entrevista com educadores (as) populares, que atuam neste espaço, teve objetivo de registrar as temáticas e práticas educativas desenvolvidas. Foram entrevistados (as) 5 organizadores(as) da ENEP e 10 educadores (as) populares(as).

Visando preservar a identidade dos (as) informantes, estes foram codificados. Os (as) informantes organizadores (as) da ENEP foram denominados por letras: A, B, C, D e E. Os (as) informantes educadores (as) populares foram identificados por números de 1 a 10.

Além da pesquisa de campo foi realizada a pesquisa documental, na qual foram consultadas as atas das reuniões da ENEP, bem como outros arquivos pertinentes.

Com objetivo de refletir sobre as práticas educativas populares, em espaço educativo não formal, e suas possíveis contribuições à Educação do Campo, foi realizado, ao final desta pesquisa, o Círculo de Cultura com estudantes do quarto ano da LICENA, futuros (as) educadores (as) do campo. Entretanto, apenas dez pessoas participaram, todas mulheres. Visando preservar a identidade, as participantes foram codificadas com os pseudônimos: Pêra, Uva, Maça, Melância, Abacate, Cana, Limão, Jaboticaba, Laranja e Maracuja.

$\mathrm{Na}$ condução deste espaço foram utilizados recursos didáticos como: tarjeta, pincel, power point, imagens de movimentos populares e da ENEP. Os recursos didáticos foram colocados no centro da roda formada pelas participantes, visando proporcionar a reflexão sobre a temática.

O projeto desta pesquisa foi registrado na Plataforma Brasil e, avaliado e aprovado, pelo Comitê de Ética em Pesquisa da Universidade Federal de Viçosa. Todos (as) os (as) informantes desta pesquisa assinaram o Termo de Consentimento Livre e Esclarecido. 


\section{Resultados e discussão}

\section{Como surgiu a Escola Nacional de Energia Popular?}

A Escola Nacional de Energia Popular (ENEP) é espaço educativo do povo, que trabalha a formação humana integral, fundamentada no trabalho e nos princípios da Educação Popular. Sua dinâmica de funcionamento (trabalho e formação) se constitui principalmente de mutirões, reuniões, encontros, assembléia popular, cursos e oficinas.

A história da ENEP se inicia na Romaria dos Trabalhadores e Trabalhadoras, no dia $1^{\circ}$ de maio de 2006, em Viçosa/MG. Discutia-se naquele momento a proposta de construir a "Universidade Popular". Iniciou-se então o diálogo com o Arcebispo de Mariana, Dom Luciano, sobre a possibilidade de uso de um terreno da Arquidiocese, localizado na zona rural da Colônia, município de Viçosa, MG. No entanto, Dom Luciano faleceu no dia 27 de agosto de 2006 e o processo ficou parado. Mas, este sonho da Universidade Popular não ficou parado, mas passou a ser recorrente nas reuniões do Movimento Evangélico Popular Eclesial - MEPE, o qual, em reunião no dia 4 de agosto de 2014, resolveu priorizar esse projeto de construção da Universidade Popular no terreno de 23 hectares da Arquidiocese de Mariana.

Após a solicitação do MEPE a Arquidiocese, veio o parecer favorável, e, no dia 11 de junho de 2015, foi assinado o acordo de comodato pela Fundação Marianense de Educação, autorizando a utilização do terreno para a implantação da Escola Nacional de Energia Popular (ENEP).

Seis organizações foram responsáveis pela fundação da ENEP: Movimento dos Atingidos por Barragens (MAB), Movimento Evangélico Popular Eclesial (MEPE), Instituto Universo Cidadão (IUC), Comissão Justiça e Paz de Paula Cândido, MG (CJP), Levante Popular da Juventude e Escola Família Agrícola Dom Luciano. Logo após sua fundação, ainda em 2015, foi criado na ENEP o Coletivo de Terapias Naturais. Atualmente outras organizações compõe a ENEP como o SindUte, a Articulação Quem Luta Educa, Movimento pela Soberania Popular na Mineração (MAM) e a Marcha Mundial das Mulheres. A 
ENEP está permanentemente em implantação, coloca-se nessa fase como "Centro de Formação- nossa Universidade Popular".

Atualmente, pequena parte da área total (23 ha) cedida a ENEP, está ocupada e manejada. Nela podemos encontrar: uma construção em ruína, atualmente usada como oficina de artesanato de bambuí; cozinha, casa com quartos, banheiros, plenária, secretaria, áreas de cultivo, espaço Saúde e Bem Viver de Terapias Naturais, curral, pasto e diversas Tecnologias Sociais Populares.

\section{Ações educativas na ENEP}

Diversas ações educativas acontecem na ENEP como cursos, oficinas, mutirões e reuniões. Algumas destas ações são organizadas pelos membrosfundadores e as organizações parceiras. Outras chegam como propostas externas que são bem acolhidas, desde que sejam coerentes com os princípios da Escola.

\section{A)Os Cursos e os/as educadores/as populares}

São realizados diversos cursos na ENEP, propostos por seus membros fundadores e organizações parceiras.

Os cursos na ENEP fazem parte de um contexto maior. Estão associados à concepção socialista da sociedade. Curso bom é curso nessa perspectiva. O entendimento da ENEP como 'guarda-chuva' de ações e de movimentos, está se consolidando quando observamos os diversos cursos promovidos neste espaço (Informante, R).

A organização proponente do curso tem a responsabilidade por tudo que se refira à sua realização. Isso não isenta a Coordenação da ENEP da sua responsabilidade pelo 'rumo' do curso, ou seja, sempre se avalia se o curso ajuda na reprodução da opressão ou na libertação do povo. Por isso é preciso uma sinergia dos cursos, com sua 'construção' refletida e encaminhada na coordenação da ENEP.

Os cursos que aconteceram no período de agosto/2018 à julho/2019, foram: Teologia Popular, Pedagogia da Alternância, Artesanato em Bambuí, 
Homeopatia Popular, Homeopatia na Agroecologia e Curso de Realidade Brasileira. Os cursos diferenciam quanto a carga horária e a dinâmica dos encontros presenciais.

Estes cursos são oferecidos por educadores (as) populares. Alguns (7) possuem o ensino superior e aprenderam os conteúdos do curso que atualmente ministram durante as aulas de graduação ou ate mesmo em outros cursos que realizaram. Outros (3) tem o ensino médio e relatam que os aprendizados vieram de alguém da família: avó, tios, parentes próximos.

Tenho somente o ensino médio, tudo que sei aprendi com minha avó, que sem sombra de dúvida, foi minha mestre. Ela mal sabia escrever o próprio nome, mas carregava dentro de si muita sabedoria. Tudo o que sou e que sei, devo a ela, que não mediu esforços para que fosse quem sou hoje". (Informante 5)

Em sua maioria os(as) educadores(as) populares começaram a dar aulas muito cedo, em sua casa ou em espaço cedido pelos(as) participantes como Associação de Moradores e Sindicatos.

Em todos estes cursos são adotadas metodologias participativas e a problematização da realidade. Isto estimula o protagonismo dos sujeitos, a dialogicidade e a troca de saberes. Observou-se semelhanças de conduta como a mística de preparo do ambiente e abertura das aulas, as cadeiras em círculo e o lanche partilhado. Diversos recursos didáticos e metodológicos são adotados e sempre com linguagem simples e acessível ao público que é diversificado e envolve estudantes do ensino médio e universitários, professores/as, agricultores/as, pessoas ligadas aos diversos movimentos sociais.

Os cursos envolvem temáticas de interesse aos povos do campo, conforme relato abaixo.

Curso de Teologia Popular: Contribui com o processo de fortalecimento das Comunidades Eclesiais de Base (CEBs) e de instrumentos de transformação da estrutura da sociedade. Atua como indicador para pessoas com aptidões relacionadas a liderar instituições religiosas, comunidades populares, que exerçam a vida sacerdotal através de ministérios transculturais, fazendo da evangelização através das Sagradas Escrituras, o ponto de convergência da essência de diversos povos, raças e etnias. $O$ curso visa contribuir com 0 
processo de formação política de militantes sociais tendo como objetivo o resgate do pensamento crítico, acerca da realidade política, social, econômica e cultural de nosso País.

Curso da Pedagogia da Alternância: capacita profissionais com atuação na Educação do Campo, a partir dos instrumentos teórico-metodológicos específicos, contribuindo com a oferta da Educação do Campo contextualizada às realidades de suas populações, de qualidade e em conformidade com as diretrizes para as escolas do campo, possibilitando assim, a integração dos movimentos. Tem como ponto central a unidade e a educação libertadora materializada, em qualquer espaço educativo.

Curso de Artesanato em Bambuí: tem por objetivo gerar saberes sobre a fabricação de móveis em bambuí e geração de renda. Curso prático, onde os participantes podem apreciar o trabalho coletivo desde a colheita do bambuí, até a confecção dos móveis. No decorrer das práticas, diversos conhecimentos sobre este ofício são partilhados. Outras temáticas da realidade também emergem e são debatidas.

Curso de Homeopatia Popular: visa divulgar a concepção de saúde sistêmica, os princípios da homeopatia e a homeopatia popular como prática de bem viver saudável, simples, de baixo custo, sem resíduos químicos ou efeitos colaterais, acessível a todas as pessoas.

Curso de Homeopatia na Agroecologia: divulga a tecnologia social da homeopatia aplicada no cuidado dos organismos vivos (humanos, plantas e animais) e ambientes (solo, água). Divulga a homeopatia como ferramenta na transição agroecológica contribuindo com o abandono definitivo dos agrotóxicos, com a saúde ambiental e com a produção de alimentos saudáveis.

Curso de Realidade Brasileira (CRB): o objetivo é fortalecer as lutas populares na região, através da articulação e da compreensão da realidade para além dos desafios de cada movimento/organização. Colabora ainda com a formação politica social do campo e da cidade, através do resgate critico acerca da realidade politica, social, econômica e cultural do País.

Todos (as) os (as) educadores (as) populares afirmam que nos cursos são partilhados conhecimentos que contribuem com o crescimento pessoal, mas 
também podem vir a gerar trabalho e renda, participando das atividades voluntárias na ENEP e afirmam que este convívio contribui com seu crescimento profissional e humano.

A ENEP é nossa casa comum. Todos os dias eu aprendo algo diferente aqui. A cada dia me sinto uma pessoa diferente e como educador esse espaço me proporciona ser um educador diferente, com metodologias diferentes, pensamentos diferentes. Esse lugar trasmite paz e ao mesmo tempo muito conhecimento. Sou ENEP por amor. (Informante 1).

Cabe ainda destacar que entrevistar os (as) educadores (as) populares, foi momento único e valioso. Foi compreender através das palavras, todo amor ao ensinar e aprender, ao buscar os caminhos para transformação social e a educação transformadora. Visualizei a amorosidade, conforme Paulo Freire.

\section{B)As Reuniões Mensais}

Segundo o informante D "as reuniões são espaços privilegiados para a discussão da prática pedagógica, e para o agir coletivo, onde os sujeitos e seus coletivos estão inseridos".

Configura-se como ambiente propicio à reflexão e análise da conjuntura política e de debates em busca de soluções aos problemas que surgem no cotidiano da Escola, além de repasse e ajuste de agendas, de planejamento e de avaliação das ações.

As reuniões mensais reúnem membros das organizações fundadoras e participantes. Duram das 08:00 às 15:00 horas. Embora a duração da reunião seja extensa ela é dinâmica e gera muitos aprendizados. Aprendemos a ouvir, a ser objetivos, críticos e propositivos, a respeitar e compreender as diversidades, a consensuar as tomadas de decisão, a refletir as ações, a planejar, dentre outros. Nas reuniões emerge a inteligência coletiva e apontam os caminhos. As organizações presentes se dividem em grupos de trabalho: limpeza e organização do espaço, preparo do alimento, mística e condução e relatoria da reunião.

A dinâmica verificada nos cursos: preparo do local, mística de abertura, cadeiras em círculo e lanche partilhado, também é verificada nestas reuniões. $A$ 
mística de abertura sempre traz algum tema da contraditória realidade para ser refletido. Os alimentos, em parte são colhidos nas áreas de cultivo da ENEP e também doados pelos participantes.

\section{C)O Mutirão na ENEP: Trabalho como Principio Educativo}

Toda quinta-feira é dia de mutirão na ENEP. É a "quinta na ENEP".

Cada semana uma das organizações que compõe a Escola é responsável em conduzir o mutirão que é aberto a comunidade. Neste dia diversas atividades de manejo e cuidado do espaço são realizadas pelo coletivo presente. Os mutirões são um marco do processo de socialização do campo. É atividade que envolve o esforço coletivo para a realização de intervenções. Essas práticas são muito comuns nas comunidades rurais onde a força de trabalho coletivo era e muitas vezes ainda é o que garante a sobrevivência das famílias (CANDIDO, 1982).

Os mutirões fortalecem as relações instituídas e garantem a multiplicação dos saberes acumulados e apreendidos, uma vez que a educação é mediada pela troca de conhecimentos entre os sujeitos, no decorrer da prática. Sendo assim, outro ponto importante dos mutirões, é a formação humana e social pelos princípios da cooperação e da coletividade, que visam fortalecer o movimento da agroecologia, do trabalho e da educação, todos interligados com a Escola Nacional de Energia Popular. Gohn (2006) acrescenta:

O trabalho em mutirão tem como função envolver a comunidade e os demais participantes, facilitando o trabalho e possibilitando a organização, em favor do bem comum, com diálogos e trocas. Neste espaço é respeitado os saberes e habilidades dos indivíduos, promovendo a troca de conhecimento, o diálogo, a formação social, formação cidadã, justiça social, formação para a liberdade. (GOHN, 2006, p.6).

$\mathrm{Na}$ ENEP o mutirão tem a intencionalidade de valorizar esta prática popular na expectativa do resgate da história, promovendo melhoria do local com e para o coletivo. O trabalho precede o dinheiro. A força do capital nada mais é do que a sua apropriação do trabalho do trabalhador. Nessa compreensão, a primeira pergunta que se faz numa proposta que busque superar a exploração 
e a opressão é: como organizar o trabalho, no seu todo e nas suas diferentes fases? A experiência da ENEP tem exigido a intensificação do trabalho no seu planejamento, buscando ser um processo, com a máxima otimização (organização) do trabalho disponível, com avaliação, reflexão, e novo planejamento.

De acordo com o entrevistado $\mathrm{F}$, a realização do trabalho, do ponto de vista organizativo, a "Quinta na ENEP" é a principal metodologia pensada no momento. Por quê? Ela possibilita convivência e cumplicidade. Ela vai atualizando, na prática, as prioridades de trabalhos, nas quais as outras iniciativas vão se inserindo. Além da "Quinta na ENEP", a logística de organização dos encontros e cursos pode ajudar na disponibilidade de trabalho, com dois mecanismos básicos: atividades coletivas e o Tempo Trabalho, para melhor organicidade do espaço.

A forma de trabalho é coletiva, com propósito comum, cada qual contribuindo conforme sua capacidade. O trabalho é um dos princípios fundamentais da ENEP, que norteia as ações desse espaço, sua organicidade e os sujeitos e os movimentos sociais presentes. No trabalho se aprende várias coisas da vida, do cotidiano, da realidade. São partilhados conhecimentos populares e acadêmicos. São desenvolvidas habilidades de trabalho coletivo, de cooperação, de união, de partilha. A ENEP exemplifica que o trabalho como princípio educativo é possível e é caminho de materializar sonhos sem colocar o capital, o dinheiro como princípio básico ou limitante.

\section{Os espaços educativos da ENEP}

Qualquer lugar na ENEP é espaço educativo. Pela sua estrutura e o que nela se encontra, seja na partilha de conhecimentos entre diversos públicos que frequentam este local: estudantes do ensino fundamental, médio e universitários, educadores (as), agricultores (as), integrantes de movimentos sociais, religiosos (as), dentre outros. Destaca-se aqui alguns destes espaços: 


\section{A)Tecnologias Sociais Populares}

As Tecnologias Sociais são produtos, técnicas, ou metodologias reaplicáveis, desenvolvidas na interação com a comunidade e que representam efetivas soluções de transformação social (FUNDAÇÃO BANCO DO BRASIL, 2019)

Diversas Tecnologias Sociais Populares estão implementadas na ENEP: horta, horta PAIS, móveis de bambuí, roda d'água, compostagem, fossa biodigestora, bioconstruções, moinho de pedra, carro de boi, homeopatia, remédios caseiros, tinta de terra, caixas secas, dentre outras. As pessoas que ali visitam têm a oportunidade de aprender sobre a tecnologia, como é construída, seu potencial para resolução de problemas, de forma simples e com baixo custo. Além destas discussões nestes espaços também se discutem questões da materialidade, das contradições, questões políticas, ambientais e sociais. Discute-se as causas das situações problemas que podem ser minimizados com tais tecnologias. Cabe ressaltar que estas causas acabam se convergindo para pontos em comum e que tem ligação direta com nosso modelo de desenvolvimento.

Diversas aulas do curso de Licenciatura em Educação do Campo da UFV acontecem nestes espaços. Na LICENA diversas TS são temas geradores no ensino contextualizado das Ciências da Natureza.

Estes espaços são propícios ao diálogo de saberes populares e científicos.

\section{B)Plenária}

Espaço de reflexão e partilha. A plenária é a área física da ENEP onde acontecem os cursos, reuniões, seminários, encontros e rodas de conversas. Por si só, a plenária já é educativa por ser uma bioconstrução, com móveis reciclados e abrigar diversas bandeiras de movimentos sociais. Muitas conversas e propostas criativas emergem neste espaço que reúne coletivos e diversidades de saberes. A plenária é um espaço democrático, de liberdade de expressão. Muitas trocas de experiências acontecem neste espaço. 


\section{C)A Cozinha}

A cozinha na ENEP também é espaço educativo. Lá podemos aprender sobre alimentação simples e saudável. Lá também se discute a origem dos alimentos e a importância da alimentação para a saúde. Lá se discute a Agroecologia, o Agronegócio, as sementes crioulas, os agrotóxicos, a cadeia alimentar, os alimentos locais, alimnetação e cultura, alimentação como ato político, dentre tantas temáticas pertinentes.

Na cozinha, por meio de mutirão são preparados os alimentos colhidos na ENEP e partilhados pelos colaboradores.

\section{O Circulo de Cultura: refletindo as contribuições da Educação Popular à Educação do Campo}

Os Círculos de Cultura estão fundamentados numa proposta pedagógica, cujo caráter radicalmente democrático e libertador propõe a aprendizagem integral, que rompe com a fragmentação e requer tomada de decisão perante os problemas vivenciados em determinado contexto. Para Freire, essa concepção promove a horizontalidade na relação educador-educando e a valorização das culturas locais, da oralidade, contrapondo-se em seu caráter humanístico, à visão elitista de educação (FREIRE, 1991).

Refletindo as contribuições da Educação Popular à Educação do Campo, a escolha pelo Círculo de Cultura, enquanto metodologia participativa, visou a troca de experiências coletivas, por meio de dialogo, permitindo aos participantes interação, troca e conhecimentos.

No Círculo de Cultura foi motivada a reflexão sobre as contribuições da ENEP, como espaço educativo não formal e de Educação Popular, à Educação do Campo.

os espaços não formais de ensino potencializam as praticas educativas populares, ampliam nossa visão de mundo, além de aprimorar nossos conhecimentos. Esses espaços se integram em nossa formação de educadores do campo. (Informante Uva).

Segundo a informante Laranja, esses espaços potencializam os aprendizados dos povos do campo. São espaços de valorização dos saberes, 
das práticas. A educação que ocorre em espaços não formais é para o povo, e age para transformar o povo.

A Educação do Campo, vem como uma nova proposta pedagógica de educação, uma educação de qualidade e que dialoga com a realidade dos povos do campo. Depois que entrei para LICENA, eu entendi melhor o papel da Educação Popular. É realmente uma educação libertadora. (Informante Limão).

A participante Pêra afirma que a ENEP promove a educação libertadora. As metodologias adotadas facilitam a compreensão. Os cursos oferecidos e a atuação da ENEP são importantíssimos para os movimentos sociais. A participante Melância acrescenta "podemos associar saberes científicos aos populares. Prova disso são as Tecnologias Sociais, que podem ser usadas no ensino de Ciências, conforme aula da LICENA".

Ressalta-se aqui a importancia dos movimentos socias e suas práticas educativas que axiliam no processo de ensino e aprendizado e na construção das identidades dos povos do campo. Essas práticas são focadas na realidade dos sujeitos, na materialidade da vida, facilitando a compreensão e contribuindo com o desenvolvimento da visão crítica e reflexiva. São voltadas à formação humana dos sujeitos, afim de transforma-lós, para que transformem o mundo.

Compreendemos que os movimentos sociais ali presentes, tambem bebem da fonte da Educação do Campo e da Educação Popular, e isso se concretiza na ENEP, pois suas praticas de atuação como metodologias participativas, trabalho educativo e formação humana. (Informante Laranja).

Assim, podemos dizer que a Escola Nacional de Energia Popular auxilia no processo de formação de educadores(as) do campo, ao praticar a Educação Popular refletida nas práticas educativas com adoção de metodologias participativas, problematizadora, dialógica, libertadora, baseada no princípio da ação-reflexão-ação.

Este Círculo de Cultura foi importante para divulgar as práticas populares da ENEP e refletir com as futuras educadoras do campo sobre as contribuições deste espaço educativo popular, não formal, com a educação de qualidade das populações do campo. 


\section{Considerações finais}

A ENEP desde sua fundação vem se consolidando como espaço educativo não formal organizado e regido pelos movimentos e organizações sociais. Foram identificadas diversas ações e espaços educativos na ENEP. Ao identificar e caracterizar as ações educativas da ENEP foi possível observar as práticas e sujeitos da educação popular.

Conhecer os (as) educadores (as) populares e suas metodologias e dinâmicas participativas adotadas na condução das aulas, indicam caminhos efetivos para a motivação e aprendizagem, o que pode inspirar a formação de educadores do campo.

Cada espaço físico da ENEP, cada componente ali presente foi construído pelo trabalho e é recurso didático. Observa-se a força desta ação coletiva e quantos aprendizados emergem. Como o trabalho permite a articulação de temas diversos e a formação integral.

O trabalho como princípio educativo é adotado no dia a dia da Escola e na prática do mutirão. É característico da Educação Popular e demonstra ser caminho efetivo de promover motivação e aprendizado. A ENEP é espaço educativo não formal, organizado por movimentos sociais, com potencial de contribuir com a formação de educadores do campo.

Foi considerado o potencial educativo da plenária, da cozinha e das Tecnologias Sociais e Populares que extrapola o ensino de conteúdos e alcança a formação política, social, ambiental e cultural dos participantes.

A proposta pedagógica da Educação do Campo encontra em consonância com a Educação Popular, que prevê a integração de saberes, o respeito e inclusão das diversidades, a problematização da realidade, a participação e a escolha de temas de interesse dos povos do campo e a proposta de formar para transformar. Ação-reflexão-ação. Na ENEP todos são educadores (as) e educandos (as), lá tudo se aprende e tudo se ensina.

Reconheceu-se ao longo desta pesquisa o potencial da ENEP em contribuir com a LICENA que também tem como pilar a Educação Popular e o Trabalho como princípio educativo. Cabe destacar ainda a Agroecologia que também é pilar da LICENA e é praticada e divulgada pela ENEP como proposta 
de desenvolvimento do campo e da cidade, com sustentabilidade e bem viver. Por fim, ao pesquisar a ENEP foi possível verificar seu potencial de impacto social e transformador, bem como a possibilidade de vir a ser uma "Universidade Popular", construída pelo povo e para o povo, atendendo suas demandas e especificidades.

\section{Referências bibliográficas}

ARROYO, M. G.; CALDART, R. S.; MOLINA, M. C. Por uma educação do campo. Petrópolis: Vozes, 2004.

ARROYO, Miguel. Ofício de mestre: imagens e auto imagens. Petrópolis: Vozes, 2009.

BATISTA, M. S. X. Os movimentos sociais cultivando uma educação popular do campo. Disponível em: http://29reuniao.anped.org.br/trabalhos/trabalho/GT06-1780--Int.pdf>. Acesso em Agosto de 2019.

BRASIL. Lei de Diretrizes e Bases da Educação Nacional: Nova LDB (Lei no 9394/96). Rio de Janeiro: Qualithmark Editora, 1997.

BRASIL. Ministério da Educação. Diretrizes operacionais para a educação básica nas escolas do campo. Brasília, DF, 2002.

CALDART, R. Educação do campo. In: CALDART, R. S.; PEREIRA, I. B.; ALENTEJANO, P.; FRIGOTTO, G. (Orgs). Dicionário de Educação do Campo. Rio de Janeiro, São Paulo: Escola Politécnica de Saúde Joaquim Venâncio, Expressão Popular, 2012. p.257-267.

CORREIA, M. C. (2009). A Observação Participante enquanto técnica de investigação. Pensar Enfermagem.

ENEP. Regimento interno da Escola Nacional de Energia Popular. ViçosaMG, 2015.

FREIRE, P. Educação como prática de liberdade. 20. ed. Rio de Janeiro: Paz e Terra, 1991.

FREIRE, P. Pedagogia do oprimido. 17 ed. Rio de janeiro: Paz e Terra, 1987. $34 p$.

FREIRE, Paulo. Pedagogia da autonomia. São Paulo: Editora Paz e Terra, 1997.

GOHM, M. G. Educação não-formal e cultura política. Impactos sobre o associativismo do terceiro setor. São Paulo, Cortez. 1999. 
GOHN, Maria da Glória. A educação não formal e a relação escola-comunidade. EccoS, São Paulo, v. 6, n. 2. p.39-65. 2014.

PALUDO, C. Educação popular em busca de alternativas: uma leitura desde o campo democrático e popular. Petrópolis: Vozes, 2014.

PALUDO, C.; MACHADO, R. C. Reflexões sobre os movimentos sociais latinoamericanos e a educação escolar. Ideação, v. 15, p. 63-81. 2012.

SILVA, M. S. Da raiz a flor: produções pedagógicas dos movimentos sociais e a escola do campo. Revista Maré: memórias, imagens e saberes do campo, n.1, p.60-93. 2015.

TRANSFORMA. Rede de Tecnologia Sociais (O que é Tecnologia Social?) Disponivel em<http:transforma.fbb.obr.br> Acesso em:3 de Dezembro de 2109.

Universidade Federal de Viçosa. Projeto Pedagógico do Curso de Licenciatura em Educação do Campo- Ciências da Natureza. 2018.

\section{Odalia Martins Machado}

odaliamartinsmachado@gmail.com

Graduada em Licenciatura em educação do Campo-Ciencias da Natureza pela Universidade Federal de Viçosa

\section{Fernanda Maria Coutinho de Andrade}

fernandamcandrade@gmail.com

Engenharia Agrônoma. Homeopata. MS e Ds em Fitotecnia. Membro do Grupo Entre Folhas-Plantas Medicinais e da Escola Nacional de Energia Popular. Professora da Licenciatura em Educação do Campo na Universidade Federal de Viçosa.

\section{Maria José de Souza}

majurucania@gmail.com

Pedagoga e bacharel em Administração com especialização em Administração Pública Municipal pela Universidade Federal de Juiz de Fora e em Políticas Públicas de Gênero e de Raça pela Universidade Federal de Ouro Preto. É especialista e mestre em Educação pela Universidade Federal e Viçosa. Membro e co fundadora da Escola Nacional de Energia Popular.

\section{Fabrício Vassali Zanelli}

fabricio.zanelli@gmail.com

Bacharel e Licenciado em Geografia e Mestre em Educação pela Universidade Federal de Viçosa. Docente do Curso de Licenciatura em Educação do CampoUFV 